\title{
Effect of L-carnitine on sperm quality during liquid storage of boar semen
}

\author{
Kang Yang ${ }^{1}$, Na Wang ${ }^{1}$, Hai-Tao Guo ${ }^{1}$, Jing-Ran Wang ${ }^{1}$, Huan-Huan Sun ${ }^{1}$, \\ Liang-Zhen Sun ${ }^{1}$, Shun-Li Yue ${ }^{1,2, *}$, and Jia-Bo Zhou ${ }^{1,2, *}$
}

\author{
* Corresponding Authors: \\ Shun-Li Yue \\ Tel: +86-0451-55191309, Fax: +86-0451-55190413, \\ E-mail: slyue@neau.edu.cn \\ Jia-Bo Zhou \\ Tel: +86-0451-55191309, Fax: +86-0451-55190413, \\ E-mail: jbzhou@neau.edu.cn \\ ${ }^{1}$ Department of Biotechnology, College of Life Science \\ Northeast Agricultural University, Harbin 150030, \\ China \\ ${ }^{2}$ Key Laboratory of Animal Cellular and Genetics \\ Engineering of Heilongjiang Province, Northeast \\ Agricultural University, Harbin 150030, China

\section{ORCID} \\ Kang Yang \\ https://orcid.org/0000-0002-5449-7986 \\ Na Wang \\ https://orcid.org/0000-0002-3933-9648 \\ Hai-Tao Guo \\ https://orcid.org/0000-0003-0185-9100 \\ Jing-Ran Wang \\ https://orcid.org/0000-0002-9681-744X \\ Huan-Huan Sun \\ https://orcid.org/0000-0002-5909-5679 \\ Liang-Zhen Sun \\ https://orcid.org/0000-0003-1982-5785 \\ Shun-Li Yue \\ https://orcid.org/0000-0001-5755-9743 \\ Jia-Bo Zhou \\ https://orcid.org/0000-0001-9177-827X
}

Submitted Jun 1, 2019; Revised Jul 12, 2019; Accepted Nov 12, 2019
Objective: This study was conducted to investigate the effect of L-carnitine on the pig semen characteristics during storage.

Methods: Spermatozoa samples were examined for spermatozoa quality and then randomly divided into 5 groups: 0 (control), 12.5, 25, 50, and $100 \mathrm{mM} \mathrm{L-carnitine.} \mathrm{Sperm} \mathrm{motility,}$ plasma membrane integrity and antioxidant parameters (total reactive oxygen species, total antioxidant capacity, and malondialdehyde) were evaluated after $0,3,5$, and 10 day cooledstorage at $17^{\circ} \mathrm{C}$. Moreover, ATP content, mitochondria activity as well as sperm-binding and in vitro fertilizing ability of preserved boar sperm were also investigated.

Results: Supplementation with $50 \mathrm{mM}$ L-carnitine could effectively maintain boar sperm quality parameters such as sperm motility and membrane integrity. Besides, we found that L-carnitine had positive effects on boar sperm quality mainly through improving antioxidant capacities and enhancing ATP content and mitochondria activity. Interestingly, by assessing the effect of L-carnitine on sperm fertility and developmental potential, we discovered that the extender containing L-carnitine could improve sperm quality and increase the number of sperms bounding to zona pellucida, without improving in vitro fertility and development potential.

Conclusion: These findings suggested that the proper addition of L-carnitine to the semen extender improved boar sperm quality during liquid storage at $17^{\circ} \mathrm{C}$.

Keywords: Boar; Sperm; L-carnitine; Liquid Storage; Antioxidant Capacity

\section{INTRODUCTION}

Artificial insemination and semen liquid storage have significantly improved the breeding potential of male animals. However, current liquid preservation techniques commonly result in compromised semen quality, and development potential of sperm is affected by the process [1]. Although special attention has already been devoted to prolonging the viability and fertilizing potential of stored liquid semen, limited improvements have been achieved [2]. A specific problem in the preservation of boar semen is reactive oxygen species (ROS) accumulation which can cause oxidative injury of sperm, resulting in damage of plasma membrane during the long-time liquid preservation $[3,4]$. Therefore, it's necessary to find an inexpensive and efficient additive to improve the quality of sperm during the storage.

Carnitine is a quaternary ammonium compound involved in metabolism in most mammals, plants and microorganisms $[5,6]$. It plays an important role in fatty acid metabolism by transporting fatty acids across the mitochondrial membrane. Carnitine forms a long chain acetylcarnitine ester transported by carnitine palmitoyltransferase I and carnitine palmitoyltransferase II located in the outer and inner mitochondrial membranes allowing 
fatty acid across the mitochondrial membranes to complete the $\beta$-oxidation pathway [7]. Carnitine is mainly synthesized in the liver and at high concentrations in mammalian epididymides and sperms. Epididymal epithelium and sperms obtain energy from the epididymal fluid by carnitine. It has been shown that high concentration of carnitine increases the motility of sperm in epididymal fluid. Besides carnitine is one of effective antioxidants. It reduces the availability of lipids for peroxidation by transporting fatty acids into the mitochondria for $\beta$-oxidation to generate ATP. It has also been reported that carnitine protects the activity of pyruvate dehydrogenase which plays a crucial role in mitochondrial respiration by trapping excess mitochondrial acetyl-CoA as acetyl-L-carnitine. The importance of carnitine in sperm quality in vivo is well recognized [8]. Previous data have indicated that dietary L-carnitine (LC) supplement could improve semen quality in human [8], chicken [9], and Pietrain boar [10] sperm. Moreover, several studies reported that extender supplemented with LC has positive effects on semen quality in some species, such as stallion [11], rooster [12], rabbit [13], and bull [14] while there are few reports about the effect of LC on liquid preserved boar sperm as well as its fertility potential. Therefore, the aim of our study was to evaluate the effect of LC supplement to Androhep semen extender on motility and membrane integrity of boar sperm. Furthermore, antioxidant parameters (total ROS [t-ROS], total antioxidant capacity [T-AOC], and malondialdehyde [MDA]) of boar sperm as well as ATP content, mitochondria activity, in vitro fertilizing ability and embryo developmental potential of preserved boar sperm were also investigated.

\section{MATERIALS AND METHODS}

All experimental procedures involving animals were conducted in accordance with the Guide for Care and Use of Animals in Research and approved by the Institutional Animal Care and Use Committee of Northeast Agricultural University. IACUC (Approval number: 20180912). Unless noted, all chemicals and media used in this study were purchased from Sigma Chemical Co (St. Louis, MO, USA).

\section{Semen collection}

Ejaculates were collected by gloved-hand method from four Yorkshire male pigs ( 1.5 to 2.5 years age). The boars were allowed at least 3 days of sexual rest between collections. The semen was transported to the laboratory at $37^{\circ} \mathrm{C}$ to $38^{\circ} \mathrm{C}$ within $30 \mathrm{~min}$. Only ejaculates containing greater than $70 \%$ sperm total motility and less than $15 \%$ morphologically abnormal spermatozoa were used in the study. After the evaluation of fresh semen quality, all fresh semen samples were pooled and divided into several equal fractions according to experimental design.

\section{Semen processing of liquid storage}

The Androhep medium containing glucose $(26 \mathrm{~g} / \mathrm{L})$, sodium citrate $(8 \mathrm{~g} / \mathrm{L})$, disodium salt dihydrate $(2.4 \mathrm{~g} / \mathrm{L})$, sodium bicarbonate $(1.2 \mathrm{~g} / \mathrm{L})$, hepes $(9 \mathrm{~g} / \mathrm{L})$, bovine serum albumin $(2.5 \mathrm{~g} / \mathrm{L})$, penethamate $(1,000,000 \mathrm{IU} / \mathrm{L})$ and streptomycin $(1 \mathrm{~g} / \mathrm{L})$ with an osmolarity of approximately $310 \mathrm{mOsm} / \mathrm{kg}$, was utilized as extender throughout this study. The spermatozoa were diluted to $1 \times 10^{7}$ spermatozoa $/ \mathrm{mL}$ in Androhep supplemented with different concentrations of LC 0 (control), $12.5,25,50$, and $100 \mathrm{mM}$. The diluted semen samples were dispersed into $100 \mathrm{~mL}$ plastic bottles and equilibrated for 2 $\mathrm{h}$ at room temperature prior to storage at $17^{\circ} \mathrm{C}$ (Thermo-box, FYL-12MC-B4, China).

\section{Assessment of sperm motility}

Total motility sperm was evaluated using the CASA system (Sperm Class Analyzer, Microptic SL, Barcelona, Spain). Semen samples were placed in a chamber and examined at $38.5^{\circ} \mathrm{C}$ under a phase-contrast microscopy system coupled to a video camera adapted to the Video Test Sperm system.

\section{Assessment of sperm membrane integrity}

Sperm membrane integrity was evaluated by the hypo-osmotic swelling test. Briefly, $10 \mu \mathrm{L}$ of sperm sample were added to $200 \mu \mathrm{L}$ of pre-warmed hypotonic solution ( $9.0 \mathrm{~g}$ of fructose and $4.9 \mathrm{~g}$ of sodium citrate per litre of distilled water with an osmolality of $150 \mathrm{mOsm}$ ) and mixed thoroughly. After a 45min incubation at $38.5^{\circ} \mathrm{C}, 200 \mu \mathrm{L} 2 \%$ glutaraldehyde were added. After incubation, $15 \mu \mathrm{L}$ of the mixture were spread with a cover slip on a warm slide. The tail coiling rate of the spermatozoa was examined using a phase-contrast microscope (Leica, Wetzlar, Germany) at a magnification of $400 \times$. Counting of cells was conducted on individual spermatozoa in five to six different medium squares until 200 sperm had been counted. There were three technical replications for all groups.

\section{Lipid peroxidation measurement}

The MDA concentrations in sperm, as an indicator of lipid peroxidation, were measured using commercially available kit (Jiancheng Bioengineering Institute, Jiangsu, China) based on the reaction with 2-thiobarbituricacid and monitored by the change of absorbance at $532 \mathrm{~nm}$ with a spectrophotometer. The MDA content in spermatozoa was expressed as nmol/ $10^{8}$ sperm cells [15].

\section{Total antioxidant capacity measurement}

The T-AOC was assessed using a total antioxidant capacity assay kit (Jiancheng Bioengineering Institute, Jiangsu, China), according to the manufacturer's instructions. The T-AOC assay was measured on a spectrophotometer at $520 \mathrm{~nm}$. 
Total reactive oxygen species measurement

Level of sperm intracellular tROS was measured using the method described by Fu et al [16]. In brief, the sperm suspension $\left(5 \times 10^{5}\right.$ cells $/ \mathrm{mL}$ spermatozoa) was incubated with 2', 7'-dichlorofluorescein diacetate (DCFH-DA; Jiancheng Bioengineering Institute, Jiangsu, China) at $37^{\circ} \mathrm{C}$ for $60 \mathrm{~min}$ in the dark, and then the labelled spermatozoa were analyzed by fluorescence microscope. The fluorescence was excited at the wave length of $485 \mathrm{~nm}$ and the corresponding emission wave length was $520 \mathrm{~nm}$. ROS fluorescence intensity was examined under a fluorescence microscope (Leica, Germany) with an analysis software system.

\section{Determination of ATP content}

ATP content was assessed using an ATP content assay kit (Jiancheng Bioengineering Institute, Jiangsu, China), according to the manufacturer's instructions. The ATP content assay was measured on a spectrophotometer (Eppendorf, Hamburg, Germany) at $636 \mathrm{~nm}$.

\section{Detection of mitochondrial activity}

Sperm mitochondrial staining was determined using Mito Tracker deep red (MTDR) fluorescence (Yeasen, Shanghai, China). Evaluations were performed by flow cytometry (BD Biosciences, Franklin Lakes, NJ, USA). In brief, the sperm suspension was incubated with MTDR (final concentration of $100 \mathrm{nM}$ ) at $37^{\circ} \mathrm{C}$ for $30 \mathrm{~min}$ in the dark, then the labeled spermatozoa were analyzed by flow cytometry (BD Biosciences, USA). The FL1 signals were detected by a $644 \mathrm{~nm}$ band-pass filter. All data were analyzed by FlowJo v7.6.1 software (TreeStar, Inc., Ashland, OR, USA).

\section{Sperm-binding and in vitro fertilization assay}

Sperm-binding assay was conducted as described previously [17]. Briefly, approximately 30 to 35 matured oocytes with a first polar body were transferred into a $50-\mu \mathrm{L}$ droplet of in vitro fertilization (IVF) medium that was covered with mineral oil and had been equilibrated at $38.5^{\circ} \mathrm{C}$ in $5 \% \mathrm{CO}_{2}$ in air. The preserved spermatozoa were resuspended in the fertilization medium to a concentration of $1 \times 10^{6}$ cells $/ \mathrm{mL}$ and capacitated by an additional $1 \mathrm{~h}$ of incubation at $38.5^{\circ} \mathrm{C}$.
Sperm samples were added to the fertilization droplets that contained the oocytes, which gave a final sperm concentration of $0.25 \times 10^{6}$ cells $/ \mathrm{mL}$. Oocytes were then coincubated with sperm for $1 \mathrm{~h}$. For sperm binding assay, the oocytes were fixed with acetic acid/ethanol (1:3) for $5 \mathrm{~h}$. After three washings, the oocytes were stained with Hoechst33342. Bound sperm were observed by confocal microscopy. For IVF, oocytes were then coincubated with sperm for 4 to $6 \mathrm{~h}$. After fertilization, oocytes were washed 3 times and cultured with 500 $\mathrm{mL}$ of porcine zygote medium in 4 -well dishes at $38.5^{\circ} \mathrm{C}, 5 \%$ $\mathrm{CO}_{2}$. The cleavage rate was determined at day 2 , and the blastocyst rate was analyzed at day 6 .

\section{Statistical analysis}

Three replicates of semen were used for in vitro evaluation of sperm parameters. All percentage data were analyzed by Chi square test using SPSS 23.0 statistical software (SPSS, Inc., Chicago, IL, USA 2007). Differential staining data were analyzed by the Student's $t$ test. Data were expressed as the mean \pm standard error of the mean, and the $\mathrm{p}$ value of less than $0.05(\mathrm{p}<0.05)$ was considered significant.

\section{RESULTS}

\section{Effect of L-carnitine on sperm quality during liquid semen storage}

The effects of LC on boar sperm motility during preservation at $17^{\circ} \mathrm{C}$ are shown in Table 1 . No significant differences were observed among treatments for up to 3 days. However, at day 5 , the total motility of spermatozoa in the groups incubated with 25,50 , and $100 \mathrm{mM} \mathrm{LC}$ respectively, was significantly higher than those of $12.5 \mathrm{mM} \mathrm{LC}$ and the control $(\mathrm{p}<0.05)$. On the day 10 the sperm total motility of LC treated groups were higher than that of the control $(\mathrm{p}<0.05)$.

Table 2 shows there were no significant differences in membrane integrity among different LC treatment groups compared with the control at the beginning of storage (at least 3 days). At day 5, higher membrane integrity was observed in LC treated groups compared to the control, especially in the 50 $\mathrm{mM}$ LC group. At day 10, the sperm membrane integrity incubated with $50 \mathrm{mM}$ LC was significantly higher than the

Table 1. Effect of L-carnitine on boar sperm motility during preservation

\begin{tabular}{|c|c|c|c|c|c|}
\hline \multirow{2}{*}{$\begin{array}{l}\text { Periods of } \\
\text { preservation (d) }\end{array}$} & \multicolumn{5}{|c|}{ Total motility (\%) } \\
\hline & $0 \mathrm{mM} \mathrm{LC}$ & $12.5 \mathrm{mM} \mathrm{LC}$ & $25 \mathrm{mM} \mathrm{LC}$ & $50 \mathrm{mM}$ LC & $100 \mathrm{mM}$ LC \\
\hline 0 & $86.07 \pm 0.71^{a}$ & $87.13 \pm 0.95^{a}$ & $86.18 \pm 1.06^{a}$ & $83.60 \pm 1.65^{a}$ & $86.06 \pm 0.89^{a}$ \\
\hline 3 & $77.97 \pm 1.03^{\mathrm{a}}$ & $73.51 \pm 1.84^{a}$ & $76.30 \pm 1.60^{a}$ & $78.40 \pm 0.55^{a}$ & $73.26 \pm 1.09^{a}$ \\
\hline 5 & $42.83 \pm 0.55^{a}$ & $48.36 \pm 1.41^{a}$ & $52.52 \pm 0.78^{b}$ & $55.40 \pm 0.56^{c}$ & $50.89 \pm 0.84^{b}$ \\
\hline 10 & $20.47 \pm 0.70^{a}$ & $25.92 \pm 1.60^{b}$ & $30.05 \pm 0.34^{b}$ & $34.07 \pm 0.45^{c}$ & $24.06 \pm 0.62^{b}$ \\
\hline
\end{tabular}

Data are represented as the mean \pm standard error of the mean $(n=3)$.

a-c Different superscript within the same row indicates significant differences at $p<0.05$. 
Table 2. Effects of L-carnitine on boar sperm plasma membrane integrity during preservation

\begin{tabular}{|c|c|c|c|c|c|}
\hline \multirow{2}{*}{$\begin{array}{l}\text { Periods of } \\
\text { preservation (d) }\end{array}$} & \multicolumn{5}{|c|}{ Plasma membrane integrity (\%) } \\
\hline & $0 \mathrm{mM} \mathrm{LC}$ & $12.5 \mathrm{mM} \mathrm{LC}$ & $25 \mathrm{mM} \mathrm{LC}$ & $50 \mathrm{mM} \mathrm{LC}$ & $100 \mathrm{mM} \mathrm{LC}$ \\
\hline 0 & $80.78 \pm 0.94^{a}$ & $82.09 \pm 1.47^{a}$ & $81.80 \pm 0.92^{a}$ & $80.15 \pm 0.10^{a}$ & $81.37 \pm 0.62^{\mathrm{a}}$ \\
\hline 5 & $33.05 \pm 0.29^{a}$ & $36.95 \pm 0.36^{b}$ & $36.34 \pm 0.49^{b c}$ & $41.28 \pm 0.57^{c}$ & $35.92 \pm 0.30^{b}$ \\
\hline 10 & $12.77 \pm 0.52^{\mathrm{a}}$ & $16.95 \pm 0.05^{b}$ & $18.35 \pm 0.68^{b c}$ & $22.98 \pm 0.75^{c}$ & $17.55 \pm 0.13^{b}$ \\
\hline
\end{tabular}

Data are represented as mean \pm standard error of the mean $(n=3)$.

LC, L-carnitine.

${ }^{a \cdot c}$ Different superscript within the same row indicates significant differences at $p<0.05$.

control $(\mathrm{p}<0.05)$.

The results demonstrated the supplement with $50 \mathrm{mM} \mathrm{LC}$ has a positive effect on boar sperm motility and membrane integrity. Thus, we used $50 \mathrm{mM} \mathrm{LC}$ for the subsequent experiments.

Effect of L-carnitine on sperm antioxidant capacity As shown in Table 3, the addition of $50 \mathrm{mM}$ LC did not induce any significant effects on antioxidant parameters (t-ROS, T-AOC, and MDA) of boar sperm compared with the control at the beginning of storage (at least 3 days). After 10 days of preservation, the MDA content and t-ROS levels of sperm increased while LC reduced MDA and ROS accumulation. On the other hand, LC supplementation notably reversed the T-AOC activity of sperm declining induced by storage $(\mathrm{p}<0.05)$. Given above results, we concluded that $50 \mathrm{mM} \mathrm{LC}$ treatment could maintain the AOC of boar sperm for at least ten days.
Effect of L-carnitine on sperm ATP levels and mitochondria activity Results of sperm ATP levels are presented in Table 4. The addition of $50 \mathrm{mM}$ LC did not have any effects on ATP content at 0 day. After 3 days of incubation, ATP content was significantly $(\mathrm{p}<0.05)$ higher in LC treated group than the control. During the following preserved periods the ATP levels were significantly $(p<0.05)$ higher in treated groups than control. Moreover, the supplement of LC had a positive effect on the mitochondrial activity rate. Mitochondrial activity was significantly $(\mathrm{p}<0.05)$ higher in LC group than the control after 5 days of preservation (Table 4 ).

\section{Effect of L-carnitine supplement on fertility and} development potential of boar sperm

As shown in Table 5, the addition of LC induced more sperms binding to zona pellucida (ZP) compared with the control

Table 3. Effects of L-carnitine on t-ROS levels, T-AOC activity, and MDA content of boar sperm

\begin{tabular}{|c|c|c|c|c|c|c|}
\hline \multirow{2}{*}{$\begin{array}{l}\text { Periods of } \\
\text { preservation (d) }\end{array}$} & \multicolumn{2}{|c|}{ t-ROS levels $(\varepsilon)$} & \multicolumn{2}{|c|}{ T-AOC activity (U/mL) } & \multicolumn{2}{|c|}{ MDA (nmol/10 sperm) } \\
\hline & $0 \mathrm{mM} \mathrm{LC}$ & $50 \mathrm{mM}$ LC & $0 \mathrm{mM} \mathrm{LC}$ & $50 \mathrm{mM} \mathrm{LC}$ & $0 \mathrm{mM} \mathrm{LC}$ & 50 mM LC \\
\hline 0 & $18.86 \pm 0.81^{\mathrm{a}}$ & $18.90 \pm 0.90^{\mathrm{a}}$ & $7.81 \pm 0.09^{\mathrm{a}}$ & $7.42 \pm 0.08^{\mathrm{a}}$ & $0.55 \pm 0.09^{a}$ & $0.61 \pm 0.15^{\mathrm{a}}$ \\
\hline 3 & $41.24 \pm 1.05^{\mathrm{a}}$ & $40.63 \pm 0.89^{a}$ & $4.58 \pm 0.14^{a}$ & $4.55 \pm 0.10^{\mathrm{a}}$ & $0.62 \pm 0.36^{a}$ & $0.66 \pm 0.49^{a}$ \\
\hline 5 & $57.07 \pm 1.42^{\mathrm{a}}$ & $47.04 \pm 1.06^{b}$ & $3.10 \pm 0.11^{\mathrm{a}}$ & $4.17 \pm 0.12^{b}$ & $1.57 \pm 0.12^{\mathrm{a}}$ & $1.11 \pm 0.08^{b}$ \\
\hline 10 & $72.77 \pm 2.95^{\mathrm{a}}$ & $61.52 \pm 0.95^{b}$ & $2.25 \pm 0.08^{\mathrm{a}}$ & $3.29 \pm 0.12^{b}$ & $2.64 \pm 0.39^{a}$ & $1.48 \pm 0.05^{b}$ \\
\hline
\end{tabular}

Data are represented as mean \pm standard error of the mean $(n=3)$.

LC, L-carnitine; t-ROS, total reactive oxygen species; T-AOC, total antioxidant capacity; MDA, malondialdehyde.

a,b Different superscript between two LC level at the same period of preservation indicates significant differences at $p<0.05$.

Table 4. Effects of L-carnitine on boar sperm ATP content and mitochondrial activity during preservation

\begin{tabular}{|c|c|c|c|c|}
\hline \multirow{2}{*}{$\begin{array}{l}\text { Periods of } \\
\text { preservation (d) }\end{array}$} & \multicolumn{2}{|c|}{ ATP content (nmol/ $10^{8}$ sperm) } & \multicolumn{2}{|c|}{ Mitochondrial activity } \\
\hline & $0 \mathrm{mM} \mathrm{LC}$ & $50 \mathrm{mM} \mathrm{LC}$ & $0 \mathrm{mM} \mathrm{LC}$ & $50 \mathrm{mM} \mathrm{LC}$ \\
\hline 0 & $13.35 \pm 0.33^{\mathrm{a}}$ & $13.25 \pm 0.40^{\mathrm{a}}$ & $83.65 \pm 0.96^{a}$ & $81.93 \pm 1.18^{\mathrm{a}}$ \\
\hline 3 & $8.99 \pm 0.42^{\mathrm{a}}$ & $10.99 \pm 0.36^{b}$ & $66.51 \pm 0.70^{\mathrm{a}}$ & $69.60 \pm 0.82^{\mathrm{a}}$ \\
\hline 5 & $7.26 \pm 0.20^{\mathrm{a}}$ & $10.30 \pm 0.19^{b}$ & $38.14 \pm 1.28^{a}$ & $57.21 \pm 1.93^{b}$ \\
\hline 10 & $4.85 \pm 0.28^{\mathrm{a}}$ & $8.55 \pm 0.26^{b}$ & $13.72 \pm 0.99^{\mathrm{a}}$ & $21.65 \pm 1.29^{b}$ \\
\hline
\end{tabular}

Data are represented as mean \pm standard error of the mean $(n=3)$.

LC, L-carnitine.

$a, b$ Different superscript between two LC level at the same period of preservation indicates significant differences at $p<0.05$. 
Table 5. Effects of L-carnitine on boar sperm fertility and developmental potential

\begin{tabular}{|c|c|c|c|c|c|c|c|}
\hline Treatment & $\begin{array}{c}\text { Oocytes } \\
\text { examined }(n)\end{array}$ & $\begin{array}{l}\text { Sperm bound to ZP } \\
\text { (n) }\end{array}$ & $\begin{array}{c}\text { Penetration rate } \\
(\%)\end{array}$ & $\begin{array}{l}\text { Monospermy } \\
\text { rate }(\%)\end{array}$ & $\begin{array}{l}\text { Total efficiency } \\
\text { of IVF }(\%)\end{array}$ & $\begin{array}{c}\text { Cleavage rate } \\
(\%)\end{array}$ & $\begin{array}{c}\text { Blastocyst rate } \\
(\%)\end{array}$ \\
\hline Control & 432 & $78.81 \pm 0.65^{a}$ & $42.26 \pm 1.16^{a}$ & $57.55 \pm 0.52^{\mathrm{a}}$ & $26.72 \pm 0.31^{\mathrm{a}}$ & $64.28 \pm 1.09^{a}$ & $27.37 \pm 0.49^{a}$ \\
\hline 50 mM L-carnitine & 570 & $91.20 \pm 1.03^{b}$ & $54.91 \pm 1.08^{b}$ & $58.17 \pm 0.80^{\mathrm{a}}$ & $30.85 \pm 0.94^{\mathrm{a}}$ & $66.03 \pm 1.51^{\mathrm{a}}$ & $29.55 \pm 0.82^{\mathrm{a}}$ \\
\hline
\end{tabular}

Sperm bound to ZP means sperm binding to the surface of the zona pellucida ( $n=$ number of bound spermatozoa per oocyte). The penetration rate means number of oocytes fertilized vs number of inseminated oocytes. The monospermy rate means number of oocytes containing one sperm head-male pronucleus vs number of penetrated oocytes. The total efficiency of fertilization means number of monospermic oocytes vs number of inseminated oocytes. The cleavage rate means the number of 2-cell embryo vs number of zygotes. The blastocyst rate means the number of blastocysts vs number of zygotes.

Values are expressed as the mean \pm standard error of the mean $(n=6)$.

$\mathrm{ZP}$, zona pellucida; IVF, in vitro fertilization.

$a, b$ Different letters indicate significant difference at $p<0.05$ in column.

$(\mathrm{p}<0.05)$. The penetration rate of IVF in LC treated group was higher than that of the control $(\mathrm{p}<0.05)$ while the total efficiency and monospermy rates were not affected by LC. Similarly, LC treatment did not exert any effects on the cleavage and blastocyst rates when the sperm was stored for 5 days (Table 5).

\section{DISCUSSION}

Liquid storage of mammalian semen can cause several timedependent structural and biochemical damages to sperm and lead to the decreased fertilizing ability of preserved sperm. In the present study, we observed a reduction of sperm total motility and plasma membrane integrity in all groups in liquid storage as time went on. However, this reduction in groups containing LC was less than the control. Furthermore, supplement of Androhep with $50 \mathrm{mM} \mathrm{LC}$ produced higher sperm motility and plasma membrane integrity compared to other groups during the period of liquid storage.

The use of exogenous antioxidants is a key strategy to alleviate time-dependent structural and biochemical damage of sperm caused by inappropriate formation of ROS in the liquid preserved boar semen [18]. Antioxidant properties of LC include the scavenging of free radicals, destruction of hydrogen peroxide and metal chelation [19] as well as inhibition of xanthine oxidase activity [20]. Among the antioxidant properties of LC, the reduction of lipid peroxidation is most widely reported and is routinely exploited in clinical settings such as reducing the severity of damage caused by ischemia-reperfusion-induced lipid peroxidation following organ surgery [21]. In this study, the MDA concentrations and t-ROS levels in the group with $50 \mathrm{mM} \mathrm{LC}$ were lower than those of the control in the meanwhile the supplementation of LC significantly increased the T-AOC activity of preserved sperm. This suggested that LC treatment could maintain the AOC of boar sperm for at least ten days. Those results of this study agree with previous reports of the beneficial effects of LC on spermatozoa of other species such as human [6], rooster [9], rat [22], cat [23], and other cell types [24-26].

Moreover, our results showed that supplement with LC could increase sperm ATP content and mitochondrial activity. This may be attributed to the role of LC in metabolism [6]. Because of the effect of facilitating fatty acids transport across the inner membrane of mitochondria for $\beta$-oxidation [27], LC plays a crucial role in mitochondrial ATP production, thus providing a better supply of energy to increase sperm motility. LC traps extra mitochondrial acetyl-CoA as acetylL-carnitine, which decreases the acetyl-CoA: free CoA ratio, enhancing the ability of the pyruvate dehydrogenase and promoting the citric acid cycle, thus increasing the production of ATP and mitochondrial activity. Moreover, LC is powerful osmolyte [20]. In fact, supplement of extender with LC leads to partial removal of $\mathrm{NaCl}$ from diluent to maintain isotonicity while $\mathrm{NaCl}$ in the solution accelerates the depletion of ATP through the activation of Na-ATPase pumps. The ATPdependent $\mathrm{Na}+\mathrm{K}+$ pump can consume up to $20 \%$ of the ATP produced by a cell in an attempt to maintain homeostasis [28]. Therefore, the motility of sperm is increased by LC through saving and promoting mitochondrial ATP production.

To assess whether LC treatment has positive effects on improving sperm fertility and developmental potential, the number of sperm binding to oocytes, total fertilization efficiency, cleavage rate, and blastocyst rate were performed using boar sperm which was preserved for 5 days in Androhep with or without $50 \mathrm{mM} \mathrm{LC}$. The ZP binding ability of sperm is crucial for sperm because sperm-oocyte interactions determine successful fertilization. Our results indicate that the sperm binding ability and the penetration rate of IVF could be improved by LC, while the total efficiency of the monospermy rates, cleavage and blastocyst rates were indeed unaffected. Therefore, the supplement of the extender with LC could improve sperm quality and increase the number of sperms bounding to $\mathrm{ZP}$, without improving in vitro fertility and development potential.

In conclusion, the supplement of semen extender with LC significantly increased boar sperm total motility and membrane integrity. Moreover, we found that the positive effects of LC on boar sperm quality were mainly due to scavenging ROS, enhancing boar sperm antioxidant properties and in- 
creasing sperm ATP levels and mitochondria activity. Despite the supplementation of LC improving sperm quality, the percentage of normospermic penetration after IVF and the devolvement potential of embryos were not influenced.

\section{CONFLICT OF INTEREST}

We certify that there is no conflict of interest with any financial organization regarding the material discussed in the manuscript.

\section{ACKNOWLEDGMENTS}

This research was supported by the National Natural Science Foundation of China (Project No. 31372311) and Open Projects of Key Laboratory of Animal Cellular and Genetic Engineering of Heilongjiang Province (Project No. KF201701).

\section{REFERENCES}

1. Pezo F, Romero F, Zambrano F, Sánchez RS. Preservation of boar semen: an update. Reprod Domest Anim 2019;54:42334. https://doi.org/10.1111/rda.13389

2. Roca J, Parrilla I, Bolarin A, Martinez EA, Rodriguez-Martinez $\mathrm{H}$. Will AI in pigs become more efficient? Theriogenology 2016;86:187-93. https://doi.org/10.1016/j.theriogenology. 2015.11.026

3. Kim S, Lee YJ, Kim YJ. Changes in sperm membrane and ROS following cryopreservation of liquid boar semen stored at $15^{\circ} \mathrm{C}$. Anim Reprod Sci 2011;124:118-24. https://doi.org/ 10.1016/j.anireprosci.2011.01.014

4. Guthrie HD, Welch GR, Long JA. Mitochondrial function and reactive oxygen species action in relation to boar motility. Theriogenology 2008;70:1209-15. https://doi.org/10.1016/ j.theriogenology.2008.06.017

5. VAZ FM, Wanders RJA. Carnitine biosynthesis in mammals. Biochem J 2002;361:417-29. https://doi.org/10.1042/bj3610417

6. Rebouche CJ, Seim H. Carnitine metabolism and its regulation in microorganisms and mammals. Annu Rev Nutr 1998; 18:39-61. https://doi.org/10.1146/annurev.nutr.18.1.39

7. Kerner J, Hoppel C. Fatty acid import into mitochondria. Biochim Biophys Acta Mol Cell Biol Lipids 2000;1486:1-17. https://doi.org/10.1016/S1388-1981(00)00044-5

8. Mongioi L, Calogero AE, Vicari E, et al. The role of carnitine in male infertility. Andrology 2016;4:800-7. https://doi.org/ 10.1111/andr.12191

9. Neuman SL, Lin TL, Heste PY. The effect of dietary carnitine on semen traits of White Leghorn roosters. Poult Sci 2002;81: 495-503. https://doi.org/10.1093/ps/81.4.495

10. Yeste M, Sancho S, Briz M, Pinart E, Bussalleu E, Bonet S. A diet supplemented with L-carnitine improves the sperm quality of Pietrain but not of Duroc and Large White boars when photoperiod and temperature increase. Theriogenology 2010; 73:577-86. https://doi.org/10.1016/j.theriogenology.2009. 10.013

11.Gibb Z, Lambourne SR, Quadrelli J, Smith ND, Aitken RJ. L-carnitine and pyruvate are prosurvival factors during the storage of stallion spermatozoa at room temperature. Biol Reprod 2015;93:104. https://doi.org/10.1095/biolreprod.115. 131326

12.Fattah A, Sharafi M, Masoudi R, Shahverdi A, Esmaeili V. L-carnitine is a survival factor for chilled storage of rooster semen for a long time. Cryobiology 2017;74:13-8. https://doi. org/10.1016/j.cryobiol.2016.12.011

13.Sarı̈zkan S, Özdamar S, Türk G, Cantürk F, Yay A. In vitro effects of L-carnitine and glutamine on motility, acrosomal abnormality, and plasma membrane integrity of rabbit sperm during liquid-storage. Cryobiology 2014;68:349-53. https:// doi.org/10.1016/j.cryobiol.2014.04.006

14.Deana R, Rigoni F, Francesconi M, Cavallini L, Arslan P, Siliprandi N. Effect of L-carnitine and L-aminocarnitine on calcium transport, motility, and enzyme release from ejaculated bovine spermatozoa. Biol Reprod 1989;41:949-55. https:// doi.org/10.1095/biolreprod41.5.949

15.Liu Q, Duan RJ, Zhou YF, Wei HK, Peng J, Li JL. Supplementing oregano essential oil to boar diet with strengthened fish oil: effects on semen antioxidant status and semen quality parameters. Andrologia 2017;49:e12764. https://doi.org/10. 1111/and.12764

16. Fu J, Yang Q, Li Y, Li P, Wang L, Li X. A mechanism by which Astragalus polysaccharide protects against ROS toxicity through inhibiting the protein dephosphorylation of boar sperm preserved at $4^{\circ} \mathrm{C}$. J Cell Physiol 2018;233:5267-80. https://doi. org/10.1002/jcp.26321

17. Miao Y, Zhou C, Cui Z, et al. Postovulatory aging causes the deterioration of porcine oocytes via induction of oxidative stress. FASEB J 2018;32:1328-37. https://doi.org/10.1096/fj. 201700908R

18.Zhao J, Jin Y, Du M, et al. The effect of dietary grape pomace supplementation on epididymal sperm quality and testicular antioxidant ability in ram lambs. Theriogenology 2017;97: 50-6. https://doi.org/10.1016/j.theriogenology.2017.04.010

19. Gülçin İ. Antioxidant and antiradical activities of L-carnitine. Life Sci 2006;78:803-11. https://doi.org/10.1016/j.lfs.2005. 05.103

20.Di Giacomo C, Latteri F, Fichera C, et al. Effect of acetyl-Lcarnitine on lipid peroxidation and xanthine oxidase activity in rat skeletal muscle. Neurochem Res 1993;18:1157-62. https:// doi.org/10.1007/BF00978367

21.Derin N, Izgut-Uysal VN, Agac A, Aliciguzel Y, Demir N. L-carnitine protects gastric mucosa by decreasing ischemiareperfusion induced lipid peroxidation. J Physiol Pharmacol 2004;55:595-606.

22.Abd-Allah ARA, Helal GK, Al-Yahya AA, Aleisa AM, Al- 
Rejaie SS, Al-Bakheet SA. Pro-inflammatory and oxidative stress pathways which compromise sperm motility and survival may be altered by L-carnitine. Oxid Med Cell Longev 2009;2: Article ID 746518. https://doi.org/10.4161/oxim.2.2.8177

23. Manee-In S, Parmornsupornvichit S, Kraiprayoon S, Tharasanit T, Chanapiwat P, Kaeoket K. L-carnitine supplemented extender improves cryopreserved-thawed cat epididymal sperm motility. Asian-Australas J AnimSci 2014;27:791-6. https:// doi.org/10.5713/ajas.2013.13565

24.Zolini AM, Carrascal-Triana E, Ruiz de King A, Hansen PJ, Alves Torres CA, Block J. Effect of addition of L-carnitine to media for oocyte maturation and embryo culture on development and cryotolerance of bovine embryos produced in vitro. Theriogenology 2019;133:135-43. https://doi.org/10.1016/ j.theriogenology.2019.05.005
25.Lowe JL, Bathgate R, Grupen CG. Effect of carbohydrates on lipid metabolism during porcine oocyte IVM. ReprodFertil Dev 2018;31:557-69. https://doi.org/10.1071/RD18043

26. Fathi M, El-Shahat KH. L-carnitine enhances oocyte maturation and improves in vitro development of embryos in dromedary camels (Camelus dromedaries). Theriogenology 2017; 104:18-22. https://doi.org/10.1016/j.theriogenology.2017.08. 006

27. Steiber A, Kerner J, Hoppel CL. Carnitine: a nutritional, biosynthetic, and functional perspective. Mol Aspects Med 2004; 25:455-73. https://doi.org/10.1016/j.mam.2004.06.006

28. Silver IA, Erecińska M. Energetic demands of the $\mathrm{Na}^{+} / \mathrm{K}^{+}$ ATPase in mammalian astrocytes. Glia 1997;21:35-45. https:// doi.org/10.1002/(SICI)1098-1136(199709)21:1<35::AIDGLIA4>3.0.CO;2-0 